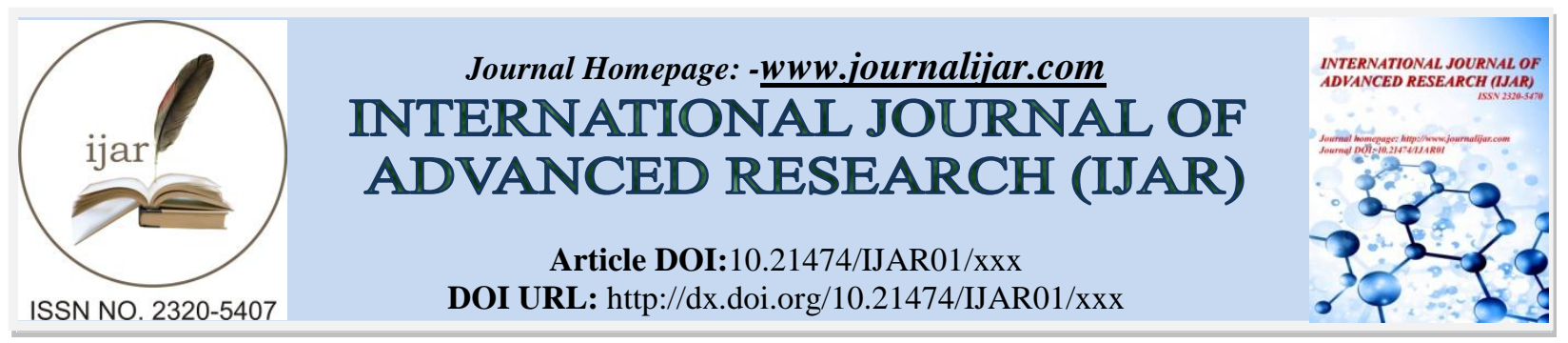

RESEARCH ARTICLE

\title{
SYNTHESIS AND CHARACTERIZATION OF ZnO/MgO NANO PARTICLES BY CURRY LEAVES THROUGH GREEN APPROACH AND THEIR PHOTOCATALYTIC APPLICATIONS.
}

\section{K. N Shravana Kumara ${ }^{1,2}$,H. P. Nagaswarupa ${ }^{* 1}$, K. R. Vishnu Mahesh ${ }^{* * 3,4}$, M.Mylarappa ${ }^{5,6}$ ,S.C.Prashantha ${ }^{1}$,D.M.K Siddeshwara ${ }^{7,2}$ and N.Raghavendra ${ }^{8}$}

1. Research Centre, Department of Chemistry, EWIT, Bengaluru-560091.

2. Research and Development Centre, Bharathiar University, Coimbatore-641046.

3. Department of Chemistry, Dayananda Sagar College of Engineering, Bengaluru-560078.

4. Dr. Premachandra Sagar Center for Advance Functional Materials, DSCE, Bengaluru-560078.

5. Research Centre, Department of Chemistry, AMC Engineering College, Bengaluru-560083.

6. Department of Studies and Research in Chemistry, B.H Road, Tumkur University Tumkur, Karnataka, India.

7. Department of Chemistry, Jyothi Institute of technology, Bengaluru-560062.

8. CMRTU, RV College of Campus, Karnataka, India, Bengaluru-560059.

\section{Manuscript Info}

\section{Manuscript History}

Received: 17 August 2016

Final Accepted: 25 October 2016

Published: October 2016

Key words:-

Synthesis, $\mathrm{ZnO} / \mathrm{MgO}$ Nano particles, curry leaves, photo degradation.

\section{Abstract}

\begin{abstract}
Present work focus onsynthesis of $\mathrm{ZnO}$ and $\mathrm{MgO}$ nanoparticles (NPs) by curry leaves through Green approach. This method is non-toxic and eco-friendly. The curry leaves extract acting as a reducing agent in thereaction. The biosynthesized NPs were characterized by different analytical techniques. X-Ray Diffractometer (XRD) for to calculate the average crystalline size, Particle Size Analyzer for average particle size, Scanning Electron Microscope (SEM) for morphological studies, UV-Visible spectroscopy (UV-Vis)for to analyze the absorption patterns. The NPs exhibit potential photocatalytic activity towards the degradation of methylene blue (MB) and Methyl red(MR)dye upon exposure to UV light. The study successfully shows a simple and ecofriendly method forthe synthesis of efficient multifunctional $\mathrm{ZnO} / \mathrm{MgONPs}$ using green synthetic approach. Photocatalytic property of the $\mathrm{ZnO} / \mathrm{MgO}$ NPs wereexamined by photo degradation of $\mathrm{MB}$ and MR under UV illumination. The biosynthesized nanoparticles showed photocatalytic activity under the UV light enhancing the degradation rate of methylene blue (MB) and Methyl red(MR), which is one of the main water-pollutant released by textile industries. The study successfully demonstrates synthesis of $\mathrm{ZnO} / \mathrm{MgO}$ NPs by simple ecofriendly route usingCurry leaves as fuel that exhibit superior photo catalytic activity.
\end{abstract}

Copy Right, IJAR, 2016,. All rights reserved.

\section{Introduction:-}

The green synthesis of metal nanoparticles using biological material as the reducing and stabilizing agents has fascinated a lot of attention and deliberation in the field of pharmaceuticals and biomedical segments as compared to the toxic chemical and physical methods due to the usage of eco-friendly, non-toxic and safe reagents during the

Corresponding Author:- H.P. Nagaswarupa, Research Center, Department of chemistry, EWIT, Bengaluru560091.

K R Vishnu Mahesh, Dept. of Chemistry, Dayananda Sagar College of Engineering, Bengaluru-560078. 
biosynthesis process [1-5].The use of plants or plant leaf extract offers a biological method for the controlled and precise synthesis of several metallic nanoparticles with well-defined diverse sizes and shapes [2].Presently, inorganic nano metal oxides $\left(\mathrm{TiO}_{2}, \mathrm{MgO}, \mathrm{CaO}\right.$ and $\left.\mathrm{ZnO}\right)$ are attracting researcher's attention due to their safety, stability and multifunctional properties. Design of materials which can be efficiently trapped and transfer energy in the form of charges is a major challenge in photo catalysis, photoluminescence (PL) and solar energy conversion fields. However, less development have been observed in materials that often exhibit unique size dependent physical and chemical properties using nanomaterials due to their large surface-to-volume ratio and quantum confinement effect. Zinc oxide $(\mathrm{ZnO})$ and Magnesium oxide $(\mathrm{MgO})$ belongs to a class of in organic metal Oxides available with a wide range of nanostructures. This Group of metal oxides is characterized by photocatalytic and Photo oxidizing ability against chemical and biological species [9]. Moreover, $\mathrm{ZnO}$ has been recognized safe by the U.S. Food and Drug Administration (21CFR182.8991). The Advantages of nanostructured $\mathrm{ZnO} / \mathrm{MgO}$ particles over other metal Nanoparticles are due to their lower cost, UV blocking properties, high catalytic activity, large surface area, white appearance and their remarkable applications in the field of medicine and agriculture [6-8].The aim of the work is the synthesis of $\mathrm{ZnO} / \mathrm{MgO}$ Nanoparticle with curry leaves as a fuel by using low cost solution combustion method. Thephotocatalytic activity were carried out to predict the catalytic properties of prepared samples.

\section{Materials and Methods:-}

Chemicals used in the current investigation were Magnesium nitrate (Merck), Zinc nitrate (Merck), methylene blue and methyl red were purchased from Merck. Curry leaves are collected in village Isamudra Chitradurga District Karnataka State.

Synthesis of $\mathrm{MgO}$ was prepared by dissolving stoichiometric amount of Magnesium nitrate/Zinc nitrate with required amount of curry leaves powder with constant stirring using cylindrical Pyrex dish. The dish was introduced into a muffle furnace preheated at $350 \pm 10^{\circ} \mathrm{C}$, solution boils and undergoes dehydration followed by decomposition of the metal nitrates. The obtained product was grinded well to fine powder. Similar method was implemented for the preparation of $\mathrm{ZnO}$ NPs.

\section{Result and Discussion:-}

\section{X-ray diffraction studies:-}

The phase purity and the crystallinity of the Nano powders were observed by powder X-ray diffractometer using the Shimadzu- 7000 X-ray diffractometer with monochromatized $\mathrm{Cu} \mathrm{Ka}$ radiation. The XRD form of $\mathrm{ZnO} / \mathrm{MgO}$ nanoparticles obtained from solution combustion synthesis were as shown in Figure $1 \mathrm{a}$ ) and Figure $1 \mathrm{~b}$ ). The peaks at $2 \theta$ values of $31.71^{\circ}, 34.41^{\circ}, 36.21^{\circ}, 47.46^{\circ}, 56.57^{\circ}, 62.76^{\circ}$ and $67.94^{\circ}$ corresponded to the crystal planes of $(100)$, (002), (101), (102), (110), (103) and (112) of zinc oxide nano particles. The diffraction peaks could be denoting as spherical phase, which was evaluated with the data from JCPDScardNo.89-7102.The strong and narrow peak signifies that the product has well crystalline nature of particles. The particle average size was calculated by the Scherer formula. In Figure $1 \mathrm{~b}$ ), the XRD results of $\mathrm{MgO}$ revealed that the structure was in cubic structure and these results were matched with JCPDS card number 75-1525. Peaks were absorbed at $36.8^{\circ}, 42.8^{\circ}, 62.1^{\circ}, 74.6^{\circ}$ and $78.5^{\circ}$ along with miller indices values (lll 111$),\left(\begin{array}{ll}2 & 00\end{array}\right),\left(\begin{array}{lll}2 & 2 & 0\end{array}\right),\left(\begin{array}{lll}3 & 1 & 1\end{array}\right)$ and $\left(\begin{array}{lll}2 & 2 & 2\end{array}\right)$ respectively. As the width of the peak increases size of particle size decreases, which look like that present material in nano range.
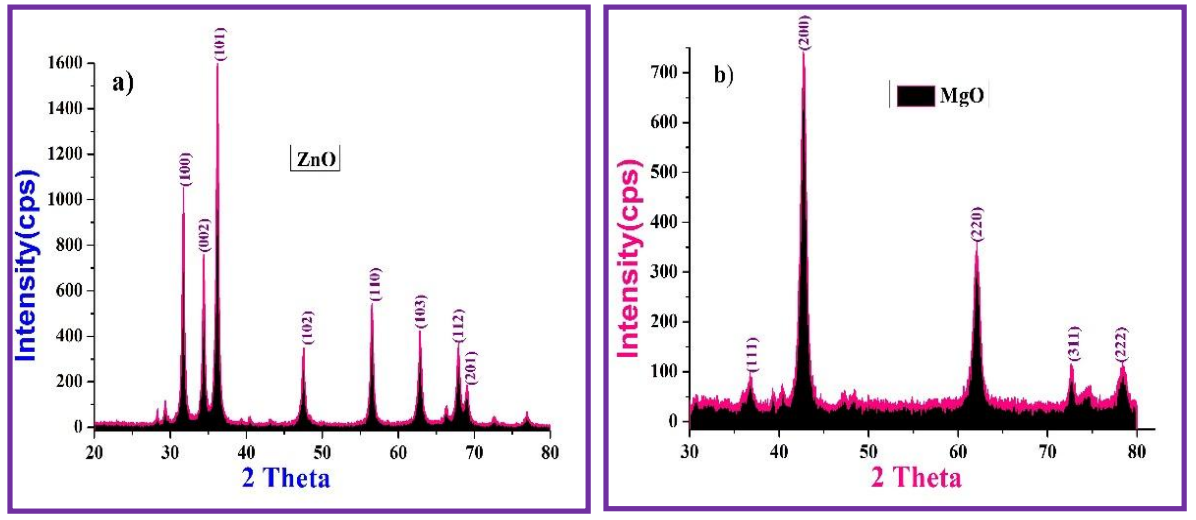

Fig 1:- $\mathrm{XRD}$ spectra of $\mathrm{ZnO}$ and $\mathrm{MgO}$ nano particles. 


\section{Transmission Electron Microscopy:-}

Transmission Electron Microscopy (TEM) is convenient to understand if amorphous or crystalline sized particles are smaller. The TEM images of $\mathrm{ZnO}$ and $\mathrm{MgO}$ nano particles were shown in the Figure. 2 a) and Figure. 2 b) respectively. From Figure 1 a) clearly showed that, $\mathrm{ZnO}$ displaysspherical like structure and Figure 2 b) representing MgOshows the hexagonal Shape and similar crystal structures without any noticeable pores.
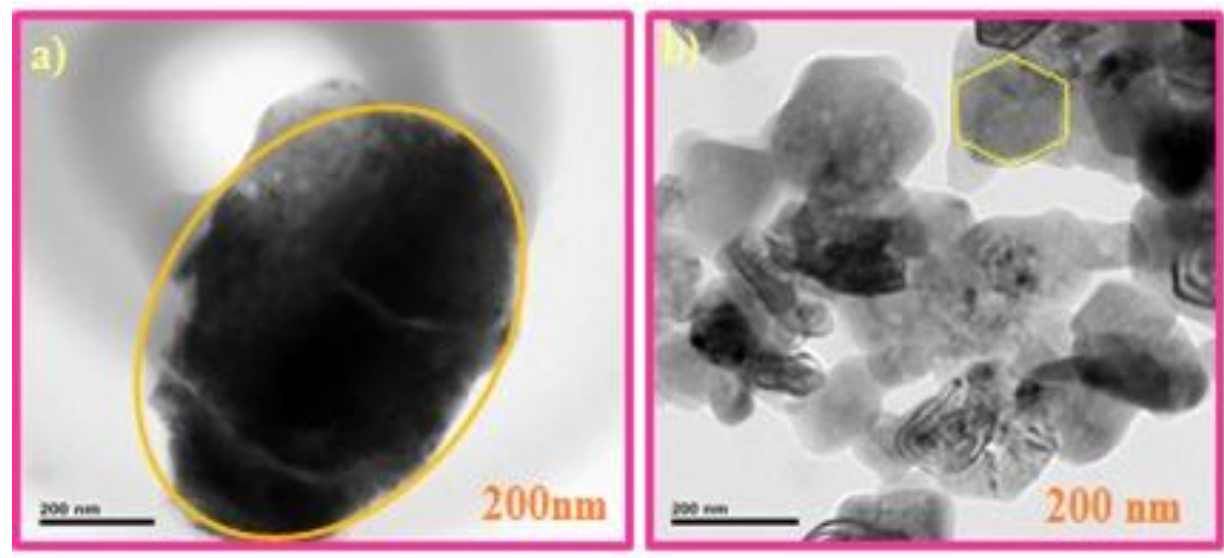

Fig 2:- TEM images of $\mathrm{ZnO}$ and $\mathrm{MgO}$ nano particles.

\section{PhotocatalyticActivity:-}

Photocatalytic studies were carried out with the help of 150-75 mm batch reactor. A catalytic load of $60 \mathrm{mg}$ nanopowders in $100 \mathrm{ml}$ of $20 \mathrm{ppm}$ dye was prepared. The dye solution and catalyst was placed in the reactor and magnetically stirred with simultaneous exposure to UV-light. Then the known volume $(4 \mathrm{ml})$ of slurry was drawn at specific intervals $(10 \mathrm{~min})$, assessed using spectrophotometer $(617 \mathrm{~nm})$ for rate of degradation. By using the following formula, the percentage (\%) of degradation of the dye can be determined.

$\%$ of degradation $=\frac{C i-C f}{C i} X 100$

WhereCi and $\mathrm{Cf}$ are initial and final dye concentrations respectively. The experiment was repeated by varying various parameters such as dye concentration, catalytic load, and irradiationtime. Photo degradation of MB and MR by $\mathrm{ZnO} / \mathrm{MgO}$ nanoparticles were studied. In Fig 3 a) to d) shows the UV-vis absorption spectra of MB and MR as a function of the catalytic reaction time. Both MB and MR solutions turns colorless after 40 min that agrees complete degradation of dye molecules by $\mathrm{ZnO} / \mathrm{MgO}$. After $40 \mathrm{~min}$ of reaction, the $\mathrm{ZnO} / \mathrm{MgO}$, Showed a good catalytic degradation of MB and MR.In Fig 4 a) to b) clearly displayed that by using prepared composite material, the MB solution with concentration of $60 \mathrm{mg} / \mathrm{L}$ can be degraded up to $97 \%$ in 40 minutes, MRup to $93 \%$ using $\mathrm{ZnO}$ particle and $70 \%$ and $91 \%$ of MB and MR degraded using $\mathrm{MgO}$ nanoparticle. 


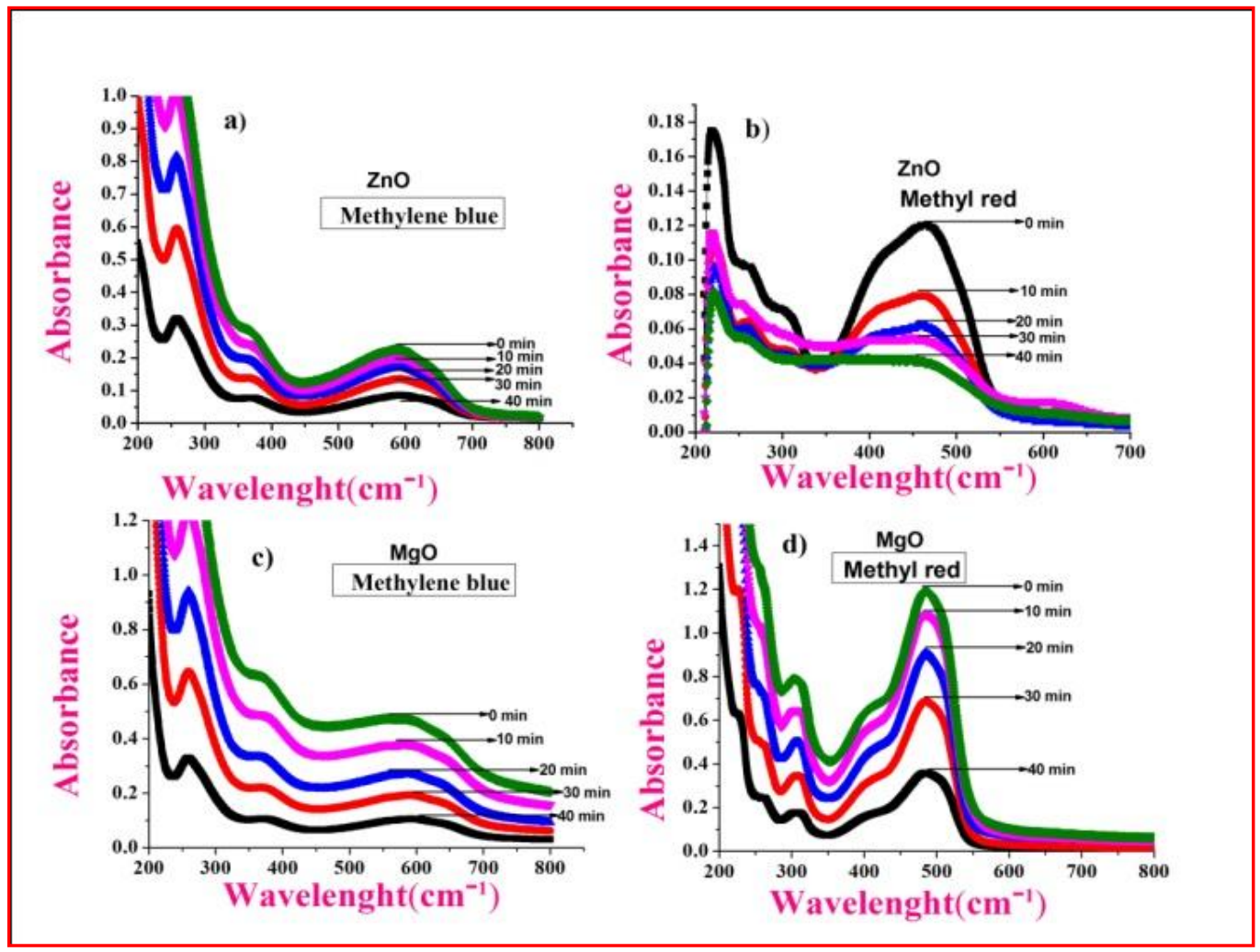

Fig 3:-UV- visible absorption spectra of $\mathrm{MB}$ and MR catalyzed by $\mathrm{ZnO}$ and $\mathrm{MgO}$
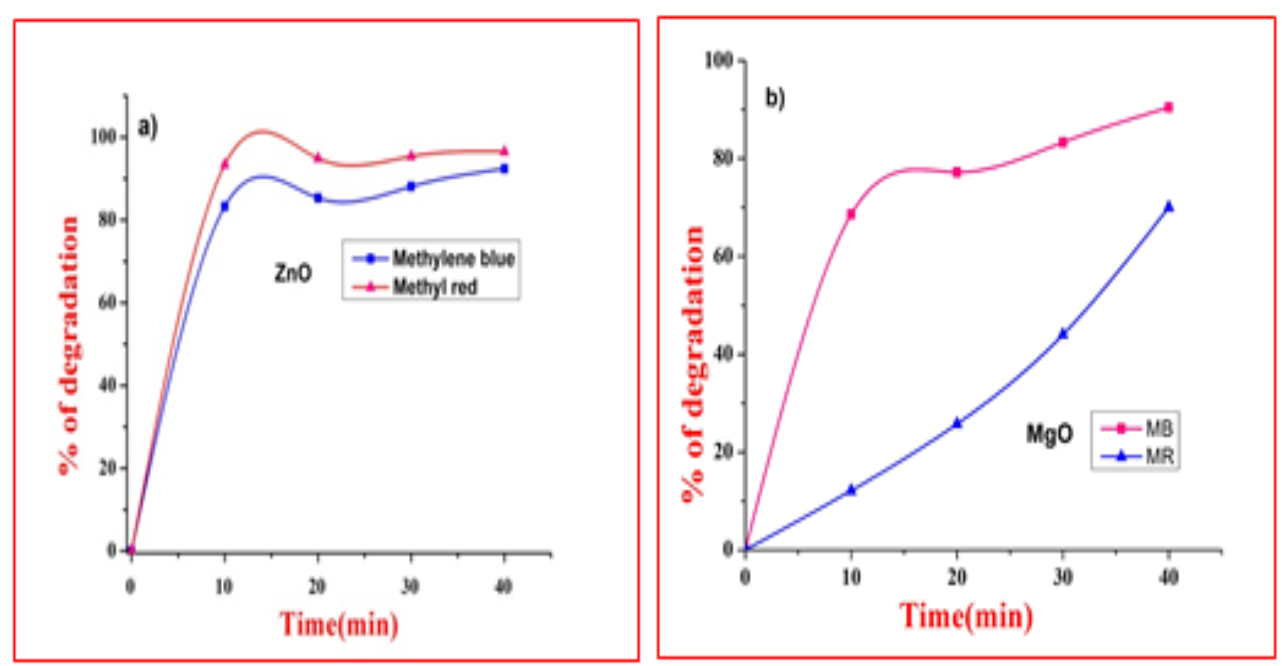

Fig 4:-Effect of Degradation of $\mathrm{MB}$ and $\mathrm{MR}$ by $\mathrm{ZnO}$ and $\mathrm{MgO}$.

\section{Conclusions:-}

The present study reports green, eco-friendly and economical approach for the green synthesized of $\mathrm{ZnO} / \mathrm{MgO}$ nano- particles using the Curry leaf extract which acts as an active reducing and stabilizing agent. The biosynthesized $\mathrm{ZnO} / \mathrm{MgO}$ nanoparticles were spherical in shape and have wurtzite structure. The synthesized $\mathrm{ZnO} / \mathrm{MgO}$ nanoparticles have shown good photocatalytic (methylene blue and methyl red degradation) activity. The photocatalytic activity studies revealed the potential of the $\mathrm{ZnO} / \mathrm{MgO}$ nanoparticles to decompose the dyes that are responsible for water pollution. Thus, it is concluded that green synthesized $\mathrm{ZnO} / \mathrm{MgO}$ nanoparticles were act as an effective photocatalytic agents. 


\section{Acknowledgment:-}

One of the author (Shravana Kumara K N) thank to the Principal and management of East West Institute of Technology for providing electrochemical work station to complete the work. We thank vision group on science and technology for their financial support. The authors HPN and SCP thanks toVGST, Govt. of Karnataka, India, (No: VGST/CISEE/2012-13/282) and (VGST/SMYSR/2014-15/411) for sanctioning the research project.

\section{Reference:-}

1. M. Moritz, M.G.Moritz, Chem.Eng.J.228, 2013, 596-613.

2. P.Rajiv,S.Rajeshwari, R.Venckatesh,Spectrochim.Acta A 112, 2013, 384-387.

3. S.D.Caruthers, S.A.Wickline,G.M.Lanza,Curr.Opin.Biotechnol.18, 2007, 26-30.

4. D. Nath, P.Banerjee, Environ.Toxicol.Pharmacol.36, 2013, 997-1014.

5. T.Szabo, J.Nemeth, I.Dekany, Colloids Surf. A, 230, 2003, 23-25.

6. M.Premanathan,K.Karthikeyan,K.Jeyasubramanian,G.Manivannan,Nanomed: Nanotech. Biol.Med.7, 2011, 184-192.

7. K.Kairyte,A.Kadys,Z.Luksiene,J.Photochem.Photobiol.B128, 2013, 78-84.

8. S.S. Kumar, P.Venkateswarlu, V.R.Rao, C.N.Rao, Int.NanoLett.3, 2013, 1-6.

9. A.Kajbafvala, H.Ghorbani, A.Paravar, J.P.Samberg, E.Kajbafvala, S. K.Sadrnezhaad, Super lattice Microstruct.51, 2012, 512-522. 